\title{
Global and Regional Tidal Volume Distribution in Spontaneously Breathing Mechanically Ventilated Children
}

\author{
Jefta van Dijk, Alette A Koopman, Robert GT Blokpoel, Sandra Dijkstra, Dick G Markhorst, \\ Johannes GM Burgerhof, and Martin CJ Kneyber
}

\begin{abstract}
BACKGROUND: Allowing the ventilated adult patient to breathe spontaneously may improve tidal volume $\left(\mathrm{V}_{\mathrm{T}}\right)$ distribution toward the dependent lung regions, reduce shunt fraction, and decrease dead space. It has not been studied if these effects under various levels of ventilatory support also occur in children. We sought to explore the effect of level of ventilatory support on $V_{T}$ distribution and end-expiratory lung volume (EELV) in spontaneously breathing ventilated children in the recovery phase of their acute respiratory failure. METHODS: This is a secondary analysis of data from a prospective clinical trial comparing 2 different ventilator modes during weaning in mechanically ventilated children $<5$ y CPAP + pressure support ventilation (PSV) and pressure control (PC)/intermittent mandatory ventilation (IMV) + PSV with the mandatory breath rate set at $25 \%$ of baseline. Using electrical impedance tomography (EIT), we assessed $V_{T}$ distribution by calculating the center of ventilation. Polynomial functions of the second degree were plotted to evaluate regional lung filling characteristics. Changes in end-expiratory impedance were calculated to assess changes in EELV. Baseline measurements were compared with measurements during CPAP/PSV, PC/IMV + PSV, and during a downward titration of the level of pressure support. RESULTS: Thirty-five subjects with a median age 4.5 (2.1-12.9) months and a median ventilation time of $4.9(3.3-6.9) \mathrm{d}$ were studied. The overall median coefficient of variation was $50.1 \%$ and not different between CPAP/PSV or PC/synchronized IMV + PSV. Regional filling characteristics of the lung identified a homogeneous $V_{T}$ distribution under all study conditions. Downtapering of the level of PSV resulted in a significant shift of the coefficient of variation toward the dependent lung regions. CONCLUSIONS: Our data showed that allowing ventilated children in the recovery phase of respiratory failure to breathe spontaneously in a continuous spontaneous ventilation mode did not negatively affect $\mathbf{V}_{\mathbf{T}}$ distribution or EELV. Key words: pediatrics; children; intensive care; pediatric intensive care; mechanical ventilation; weaning; spontaneous breathing; electrical impedance tomography. [Respir Care 0;0(0):1-•. (C) 0 Daedalus Enterprises]
\end{abstract}

\section{Introduction}

Allowing the mechanically ventilated patient to breathe spontaneously can be a double-edged sword. Experimental studies and observational data from adults reported that spontaneous breathing in the presence of severe lung injury may lead to patient self-inflicted lung injury. ${ }^{1}$ Vigorous breathing may cause injurious transpulmonary pressure swings leading to lung inflammation. ${ }^{2,3}$ On the other hand, experimental and clinical physiology studies demonstrated that the posterior part of the diaphragm contracts more than the anterior part during spontaneous breathing. ${ }^{4,5}$ This resulted in distribution of the tidal volume $\left(\mathrm{V}_{\mathrm{T}}\right)$ toward the dependent, well-perfused lung regions, thereby attenuating ventilation-perfusion mismatch and a reduced shunt fraction, decreasing lung collapse and lung inflammation. ${ }^{5-10}$

The term "spontaneous breathing during mechanical ventilation" can refer to a continuous spontaneous ventilation mode (CSV) such as CPAP with or without pressure support or a mode of ventilation that allows the patient to trigger the ventilator with or without PEEP. It is unknown if the physiological benefits of spontaneous breathing also occur in mechanically ventilated children. One study reported a shift of ventilation toward the nondependent lung regions and a significant reduction in end-expiratory lung volume (EELV) when spontaneous breathing was 


\section{Global and Regional $V_{T}$ In Mechanically Ventilated ChildRen}

eliminated through the induction of anesthesia. ${ }^{11}$ It may also be surmised that in especially small children there is less gravitational effect on $\mathrm{V}_{\mathrm{T}}$ distribution because of a smaller anteroposterior chest wall dimension. ${ }^{12}$

We hypothesized that pediatric patients with resolving respiratory failure breathing spontaneously in a ventilation mode (CPAP + pressure support) that allows the patient to trigger the ventilator and delivers at the same a low mandatory breath rate (thereby having these breaths act as a sigh) would display better global and regional lung aeration as well as a more homogeneous $\mathrm{V}_{\mathrm{T}}$ distribution. We tested this hypothesis through a secondary analysis of data collected from a parent trial comparing 2 different modes of support during pediatric ventilator weaning using electrical impedance tomography (EIT). EIT offers a unique opportunity for a noninvasive, radiation-free, and bedside imaging technique of real-time global and regional lung aeration by measuring relative impedance changes in lung tissue, and it creates images of local ventilation. ${ }^{13-16} \mathrm{We}$ also explored the effect of the level of pressure support on global and regional $\mathrm{V}_{\mathrm{T}}$ distribution measured with EIT.

\section{Methods}

This is a secondary physiology-driven analysis of data from a clinical study comparing 2 different ventilator modes during weaning in children with or without acute lung injury performed in the 20-bed tertiary medical-surgical pediatric ICU of the Beatrix Children's Hospital, University Medical Center Groningen (Groningen, the Netherlands). The study was approved by the institutional review board, and written informed consent was obtained from parents or legal caretakers.

Subjects with resolving respiratory failure were included if they were younger than $5 \mathrm{y}$ of age, ventilated for at least $24 \mathrm{~h}$, and were in the weaning phase of their disease trajectory according to the clinical team; that is, subjects were able to trigger the ventilator, had sufficient respiratory drive, and stable ventilator settings and hemodynamics (ie, no need for increase in vasoactive drugs and/or fluid

\footnotetext{
Drs van Dijk and Blokpoel and Mss Koopman and Dijkstra are affiliated with Department of Paediatrics, Division of Paediatric Critical Care Medicine, Beatrix Children's Hospital, University Medical Center Groningen, University of Groningen, Groningen, the Netherlands. Dr Markhorst is affiliated with Department of Paediatrics, Division of Paediatric Critical Care Medicine, VU University Medical Center, Amsterdam, the Netherlands. Mr Burgerhof is affiliated with Department of Epidemiology, University Medical Center Groningen, The University of Groningen, Groningen, the Netherlands. Dr Kneyber is affiliated with Department of Paediatrics, Division of Paediatric Critical Care Medicine, Beatrix Children's Hospital, University Medical Center Groningen, University of Groningen, Groningen, the Netherlands and Critical Care, Anaesthesiology, Peri-operative and Emergency Medicine, University of Groningen, Groningen, the Netherlands.
}

\section{QUICK LOOK}

\section{Current knowledge}

The approach to pediatric ventilator liberation is heterogenous. It is unclear if children should be weaned using full pressure support or in a ventilator mode with a backup mandatory breath rate. Theoretically, the first may lead to a better distribution of the tidal volume $\left(\mathrm{V}_{\mathrm{T}}\right)$ toward the dependent lung zones. $\mathrm{V}_{\mathrm{T}}$ distribution can be studied using electrical impedance tomography.

\section{What this paper contributes to our knowledge}

We found that there was no difference in distribution of $\mathrm{V}_{\mathrm{T}}$ or in end-expiratory lung volume between weaning using full pressure support or in a ventilator mode with a backup mandatory breath rate, irrespective of the level of pressure support applied. This data may contribute to a better understanding of ventilator liberation in children.

challenges at least $6 \mathrm{~h}$ prior to enrollment). Excluded were patients born prematurely with a corrected gestational age $<40$ weeks, congenital or acquired neuromuscular disorders, congenital or acquired paralysis of the diaphragm, severe traumatic brain injury (ie, Glasgow coma score $<8$ ), uncorrected congenital heart disorder, chronic lung disease, and severe pulmonary hypertension.

In our unit, patients are ventilated with a time-cycled, pressure-limited synchronized mode of ventilation with pressure support. Children $<10 \mathrm{~kg}$ are ventilated using pressure-controlled (PC)/assist-control intermittent mandatory ventilation (IMV), whereas children $>10 \mathrm{~kg}$ with lung injury are ventilated using PC/synchronized IMV (SIMV) (PC/SIMV + pressure support ventilation [PSV]) and those without lung injury using volume control (VC) with preset $\mathrm{V}_{\mathrm{T}}$ with pressure support (VC/IMV + PSV).

An expiratory $\mathrm{V}_{\mathrm{T}}$ of $5-7 \mathrm{~mL} / \mathrm{kg}$ actual bodyweight was targeted. $\mathrm{V}_{\mathrm{T}}$ was measured at the $\mathrm{Y}$-piece of the patient Dr Kneyber discloses relationships with Vyaire and Applied Biosignals.
The remaining authors have disclosed no conflicts of interest.

Study performed at Department of Pediatrics, Division of Pediatric Critical Care Medicine, Beatrix Children's Hospital, University Medical Center Groningen, University of Groningen, Groningen, the Netherlands.

Supplemental material related to this paper is available at http://rc. rcjournal.com.

Correspondence: Jefta van Dijk MD, Beatrix Children's Hospital, University Medical Center Groningen, Internal Postal Code CA 62, PO Box 30.001, 9700 RB, Groningen, the Netherlands. E-mail: j.van.dijk01@umcg.nl.

DOI: $10.4187 /$ respcare.09190 


\section{Global and Regional V V IN Mechanically Ventilated Children}

circuit (VarFlex, Vyaire, Mettawa, Illinois). Peak inspiratory pressures were aimed at $<28 \mathrm{~cm} \mathrm{H}_{2} \mathrm{O}\left(<32 \mathrm{~cm} \mathrm{H}_{2} \mathrm{O}\right.$ when there was an increased chest wall elastance) with an initial PEEP of 4-6 $\mathrm{cm} \mathrm{H}_{2} \mathrm{O}$ in all subjects. If necessary, PEEP was titrated and guided by the $\mathrm{F}_{\mathrm{IO}_{2}}$ to maintain an $\mathrm{S}_{\mathrm{pO}_{2}}$ of $92-97 \%$. Flow trigger was set between 0.5 and 1.0 $\mathrm{L} / \mathrm{min}$. A heat moisture exchanger (Gibeck, Teleflex Medical, Vianen, the Netherlands) was in situ between the patient circuit and the endotracheal tube (KimVent, Microcuff Endotracheal Tube, Kimberly-Clark, Dallas, Texas).

\section{Data Acquisition}

In the parent study, we studied 2 different ventilator modes during weaning (that is, CSV [subject was on CPAP/PSV] versus partial ventilatory support [subject was on PC/SIMV with set mandatory breath rate at $25 \%$ of the rate before enrolment]). Each subject underwent a period with CPAP/PSV and PC/IMV + PSV (in random order) and subsequently a period with downgrading of PSV (see related supplemental material at http://rc. rcjournal.com).

For baseline recording, data were stored during $5 \mathrm{~min}$ of stable breathing, and the EIT recordings were performed during the last $60 \mathrm{~s}$. Based on the randomization order, subjects were then switched to CPAP/PSV with the level of PSV similar to the added pressure above PEEP during baseline measuring. After $5 \mathrm{~min}$ of stabilization, respiratory data were again recorded for 5 min including an EIT recording in the last minute. After a resting period of $10 \mathrm{~min}$ where ventilator settings were similar to baseline, the mandatory breath rate was set at an arbitrarily chosen 25\% from baseline. Finally, all subjects were switched to the CPAP/PSV mode using the same ventilator settings as in the spontaneous breathing mode. Then the level of pressure support was reduced 3 times by $2 \mathrm{~cm} \mathrm{H}_{2} \mathrm{O}$ per step. Each step consisted of $5 \mathrm{~min}$ of stabilization followed by 5 min of recording ending with a 1 min EIT recording.

EIT data were acquired using the Göttingen MF II system (CareFusion, Yorba Linda, California). For this purpose, 16 electrodes (BlueSensor BR-50-K, Ambu, Copenhagen, Denmark) were applied circumferentially on the subject's chest at the level of the intermammary line. Each electrode injects a small unit of current that will cause a potential difference (because of different bioelectrical tissue characteristics) that is measured by a pair of passive electrodes, which are not used for injection. Subsequently, all adjacent electrode pairs are used for current injection and by doing so completing one data cycle of 208 different surface potentials (16 current injections x 13 voltage measurements). ${ }^{17-19}$ Using the back-projection image reconstruction algorithm, a relative change in impedance $(\Delta \mathrm{Z})$ can be calculated. Whereas $\Delta \mathrm{Z}$ is calculated through $\left(\mathrm{Z}_{\text {inst }}-\right.$ $\left.Z_{\text {ref }}\right) Z_{\text {ref }}$ (where $Z_{\text {inst }}$ is the instantaneous local impedance and $Z_{\text {ref }}$ the reference impedance), determined from each data cycle. ${ }^{20,21}$ With a modification of the concept by Milic-Emili et al, regional filling characteristics of the lung also can be studied by fitting regional versus global $\mathrm{V}_{\mathrm{T}}$ evaluated by EIT to a polynomial function of the second degree. ${ }^{18,22}$ Prior to the measurements, a $30 \mathrm{~s}$ during reference measurement is made with a $13 \mathrm{~Hz}$ scan rate, and all the measurements were related to this measurement. Oneminute EIT recordings were made with a scan rate of $13 \mathrm{~Hz}$ at baseline and after each period following a 5-min stabilization period (see related supplemental material at http://rc. rcjournal.com).

At the time of EIT data acquisition, we recorded subject physiology data (breathing frequency and transcutaneously measured $\mathrm{S}_{\mathrm{pO}_{2}}$ ) (Masimo, Irvine, California) as well as ventilator data (AVEA, Vyaire) including mean airway pressure $\left(\overline{\mathrm{P}}_{\mathrm{aw}}\right)$, minute volume $\left(\dot{\mathrm{V}}_{\mathrm{E}}\right)$, expiratory $\mathrm{V}_{\mathrm{T}}$, and endtidal $\mathrm{CO}_{2}\left(\mathrm{P}_{\mathrm{ETCO}_{2}}\right)$.

Ventilator settings (mandatory breath rate, inspiratory pressures, $\mathrm{PEEP}, \mathrm{F}_{\mathrm{IO}_{2}}$, and inspiratory time) were also recorded. Subject demographics were obtained to characterize the study cohort, including gender, age, weight, 24-h Pediatric Risk of Mortality III score, admission diagnosis, and endotracheal tube size. ${ }^{23}$ The Pediatric Mechanical Ventilation Consensus Conference definition was used to stratify subjects based on their admission diagnosis (ie, the clinical phenotype), and pediatric ARDS was identified using the Pediatric Acute Lung Injury Consensus Conference definition. ${ }^{24,25}$

\section{Data Analysis}

EIT data were analyzed using Auspex (V1.6, VUmc, Amsterdam, the Netherlands) and MATLAB (MathWorks, Natick, Massachusetts). Both the respiratory and cardiac components of the EIT signal were identified in frequency spectra generated from all EIT measurements using fast Fourier transformation. The EIT data were low-pass filtered with a cutoff frequency of $2 \mathrm{~Hz}$ to eliminate small impedance changes synchronous with the heartbeat. ${ }^{26}$ Then, local end-inspiratory to end-expiratory amplitudes of relative impedance changes were calculated in all image pixels, and functional scans showing the distribution of regional $V_{T}$ were generated.

An EIT image is a cross-sectional image of the chest showing regions from the lungs, chest wall, and mediastinum. (Fig. 1) The outer boundaries of the lungs were determined from functional EIT images based on the calculation of local impedance variation with time. ${ }^{18}$ The impedance variations of the chest wall and mediastinum are lower than those of the lungs. We, therefore, set the threshold 


\section{Global and Regional V $V_{T}$ In Mechanically Ventilated ChildRen}
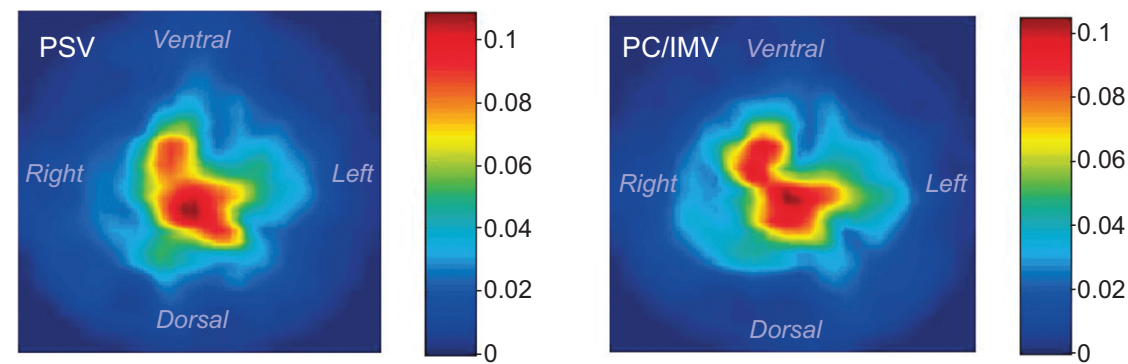

Fig. 1. Functional electrical impedance tomography (EIT) image during pressure support ventilation (PSV) and pressure-controlled (PC)/ synchronized intermittent mandatory ventilation (SIMV) (PC/SIMV) ventilation with a set mandatory breath rate at $25 \%$ of the rate before enrollment. The color red is an indication of high-impedance changes, whereas the green and blue colors indicate low-impedance changes. As can be seen between the 2 different weaning methods, there was no (significant) change.

Table 1. Cohort Demographics

\begin{tabular}{|c|c|}
\hline \multicolumn{2}{|l|}{ Subjects, $N=35$} \\
\hline Male, $\%$ & 68.6 \\
\hline Age, months, $\%$ & $4.53(2.06-12.90) 74.3$ \\
\hline Weight, kg & $6.48(4.55-9.87)$ \\
\hline PRISM III (24 h) score & $3(1-4)$ \\
\hline PIM 2 (24 h) score & $-4.38(-4.72$ to -4.09$)$ \\
\hline \multicolumn{2}{|l|}{ Admission diagnosis, $n$} \\
\hline Respiratory & 34 \\
\hline Postoperative & 1 \\
\hline \multicolumn{2}{|l|}{ PEMVECC clinical phenotype classification, \% } \\
\hline Normal lung mechanics & 2.9 \\
\hline Obstructive lung disease & 14.3 \\
\hline Restrictive lung disease & 14.3 \\
\hline Mixed lung disease & 68.6 \\
\hline \multicolumn{2}{|l|}{ Baseline ventilation mode, $n$} \\
\hline Pressure assist control & 22 \\
\hline CPAP/PSV & 13 \\
\hline \multicolumn{2}{|l|}{ Tube size, $n$} \\
\hline $3.0 \mathrm{~mm}$ & 7 \\
\hline $3.5 \mathrm{~mm}$ & 11 \\
\hline $4.0 \mathrm{~mm}$ & 14 \\
\hline $4.5 \mathrm{~mm}$ & 3 \\
\hline Duration of mechanical ventilation, $d$ & $4.86(3.35-6.89)$ \\
\hline HFOV, $\%$ & 48.6 \\
\hline HFOV duration, $d$ & $2.38(1.52-3.19)$ \\
\hline Time between enrollment and extubation, $\mathrm{h}$ & $23.04(17.80-44.56)$ \\
\hline Pedidatric ICU length of stay, $d$ & $5.92(4.24-9.00)$ \\
\hline \multicolumn{2}{|c|}{$\begin{array}{l}\text { Admission diagnosis is based on the definitions in the Pediatric Mechanical Ventilation } \\
\text { Consensus Conference (reference 25). Data shown as median (IQR) unless otherwise specified. } \\
\text { PRISM III = Pediatric Risk of Mortality III } \\
\text { PIM } 2 \text { = Pediatric index of mortality } \\
\text { PEMVECC = Pediatric Mechanical Ventilation Consensus Conference } \\
\text { PSV = pressure support ventilation } \\
\text { HFOV = high-frequency oscillatory ventilation }\end{array}$} \\
\hline
\end{tabular}

impedance variation of these structures at a value corresponding to $20 \%$ of the maximum variation within the functional image and used it as the limit to define the EIT lung regions. ${ }^{27,28}$ Regional pixel $\mathrm{V}_{\mathrm{T}}$ from these EIT lung regions were then plotted versus the global $\mathrm{V}_{\mathrm{T}}$ calculated from the sum of all image pixels within the whole cross-section from one inspiration. The regional and global tracings of relative impedance change beginning at inspiration and ending at expiration were normalized to the regional and global tidal end-inspiratory to end-expiratory difference in relative impedance change; thus, they are given as fractions of $1.0 .^{28}$ The regional versus global $\mathrm{V}_{\mathrm{T}}$ plots were subsequently fitted by a polynomial function of the second degree: $y=a x^{2}+b x+c$. The quality of fitting was assessed by simultaneously plotting fitted and measured data points. Fittings were accepted if the $\mathrm{R}^{2}$ was $\geq 0.90$. The curvature of the plot is characterized by the polynomial coefficient of the second-degree $a$. A polynomial coefficient of the second degree of nearly zero $(-0.2-0.2)$ indicates a regional $\mathrm{V}_{\mathrm{T}}$ change that occurs almost homogeneously during inspiration. Negative values $(<-0.2)$ of the polynomial coefficient of the second degree indicate that the degree of impedance change in region of interest is greater at the beginning of the inspiratory cycle compared to global but eases off toward the end, suggesting hyperinflation of that region of interest. A positive polynomial coefficient of the second degree $(>0.2)$ indicates that the degree of impedance change at the beginning of the inspiratory cycle is less in the region of interest compared to global but increases toward the end of the inspiratory cycle, suggesting tidal recruitment. ${ }^{18}$ To assess ventral to dorsal distribution of regional filling, profiles of average polynomial coefficients were generated. In each of the 32 rows of the 32 $\times 32$ matrix of polynomial coefficient values, 2 average polynomial coefficients were calculated from 16 individual pixel values in the right and 16 in the left halves of the matrix, respectively.

To objectify the occurrence of pendelluft, a MATLAB script was developed (MathWorks) that calculated for each recorded breath in the $32 \times 32$ pixel matrix if there was both a decrease and increase in relative impedance, suggestive for shifting of air. 


\section{Global and Regional $V_{T}$ In Mechanically Ventilated ChildRen}

Table 2. Subject Vital Parameters Compared to the Baseline or the Previous Step in the Stepwise Reduction of the Amount of Pressure Support

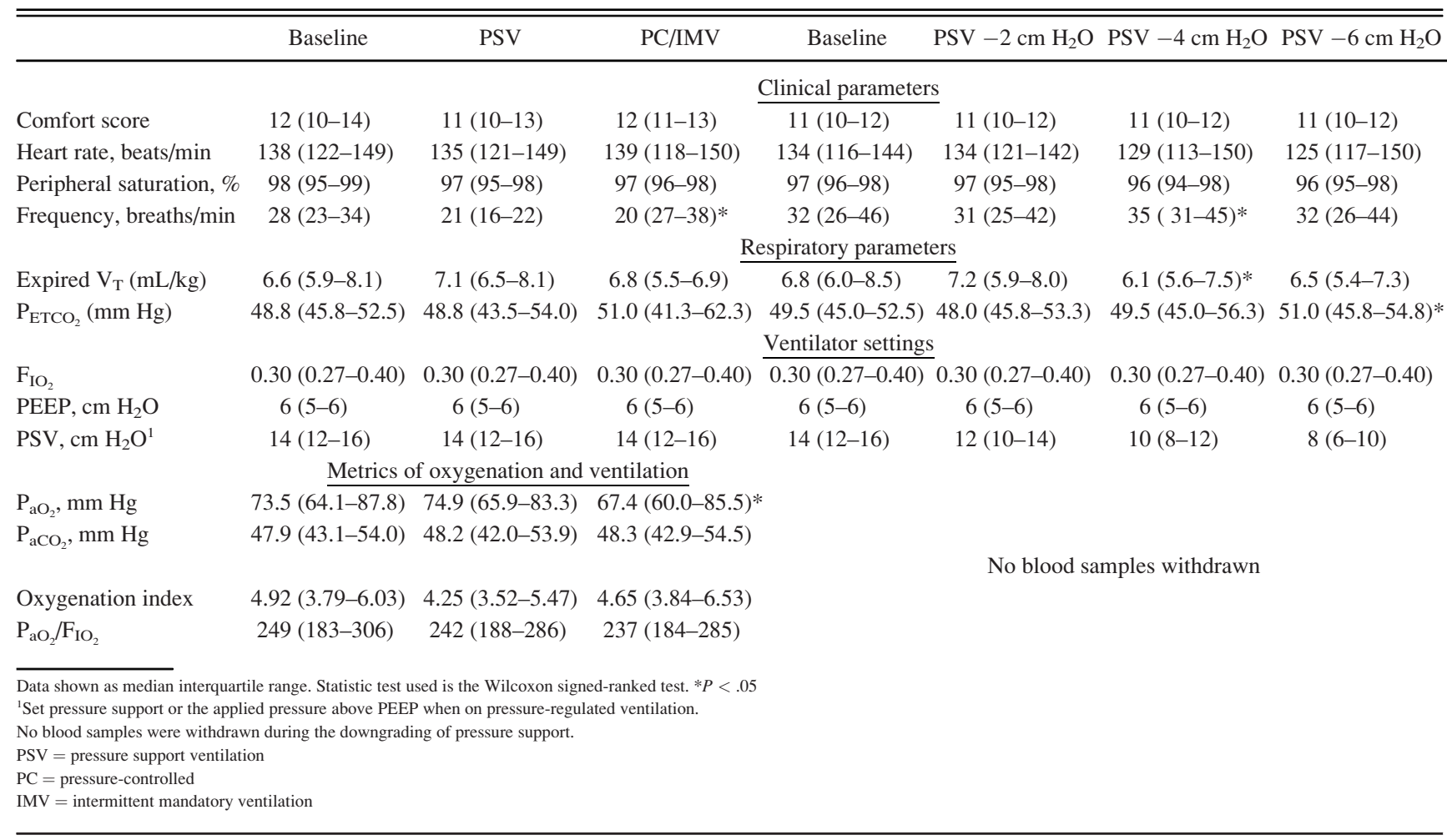

\section{Statistical Analysis}

Data of all variables were assessed for normality using the Kolmogorov-Smirnov test. Descriptive data were expressed as median (25-75 interquartile range) or percentage $(\%)$ of total. For the univariate analysis, data measured during the 2 ventilator modes and gradual reduction of PSV, the Wilcoxon signed-rank test was used. Linear regression analysis was used to study the correlation between median polynomial coefficients of the second degree and lung mechanics and parameters for gas exchange. Statistical analysis was performed using SPSS v23 (IBM, Armonk, New York). $P$ values $<.05$ were considered statistically significant.

\section{Results}

Data from 35 subjects (68.6\% male) with an age of 4.5 (IQR 2.1-12.9) months and weight 6.5 (IQR 4.6-9.9) kg were analyzed (Table 1). Subjects were ventilated for 4.9 (IQR 3.3-6.9) d and studied after 87 (IQR 58-129) h of ventilation. Neuromuscular blocking agents were used in $77.1 \%$ of the cohort. Time between stopping neuromuscular blocking agents and study enrollment was 65.4 (IQR 30.1-188.5) h. Average pediatric ICU length of stay was 5.9 (IQR 4.29.0) d. (Table 1) Ventilatory support remained unchanged after enrollment during the study period (ie, $\mathrm{PEEP}, \mathrm{F}_{\mathrm{IO}_{2}}$, and level of pressure support). Overall, no significant differences with clinical importance were found in respiratory physiology variables such as breathing frequency, $\mathrm{P}_{\mathrm{ETCO}_{2}}$, or $\mathrm{F}_{\mathrm{IO}_{2}}$ (Table 2).

Overall median center of ventilation was $50.1 \%$ (IQR 47.2-52.9) and was not different between the 2 ventilator modes (Fig. 2), indicating that there was no gravity-dependent $\mathrm{V}_{\mathrm{T}}$ distribution or preference of $\mathrm{V}_{\mathrm{T}}$ toward the nondependent or dependent lung zones. Similar findings were made for EELV (Fig. 3), albeit that there was a statistically significant difference. EELV was significantly lower during CPAP/PSV compared with PC/SIMV+PSV. Analysis of regional filling characteristics showed an overall coefficient of 0.10 (IQR $-0.20-0.49$ ) and was not different between the 2 ventilator modes, indicating a homogenous distribution of $\mathrm{V}_{\mathrm{T}}$ throughout the lung (Fig. 4). Pendelluft was not observed.

Coefficient of variation decreased significantly when the level of pressure support was tapered down to $6 \mathrm{~cm}$ $\mathrm{H}_{2} \mathrm{O}$ from baseline (Fig. 2). We also observed a significant decrease in in EELV from 7.1 (IQR -9.6 to -5.4) to -5.5 (IQR -7.5 to -4.0 ) during pressure support reduction (Fig. 3), but there was no change in the distribution of $\mathrm{V}_{\mathrm{T}}$ throughout the lung represented by the regional filling characteristics (Fig. 5).

\section{ReSPIRATORY CARE $\bullet \bullet \bullet \mathrm{VOL} \bullet \mathrm{No}$}

Copyright (C) 2021 Daedalus Enterprises ePub ahead of print papers have been peer-reviewed, accepted for publication, copy edited and proofread. However, this version may differ from the final published version in the online and print editions of RESPIRATORY CARE 


\section{Global and Regional V $V_{T}$ In Mechanically Ventilated Children}
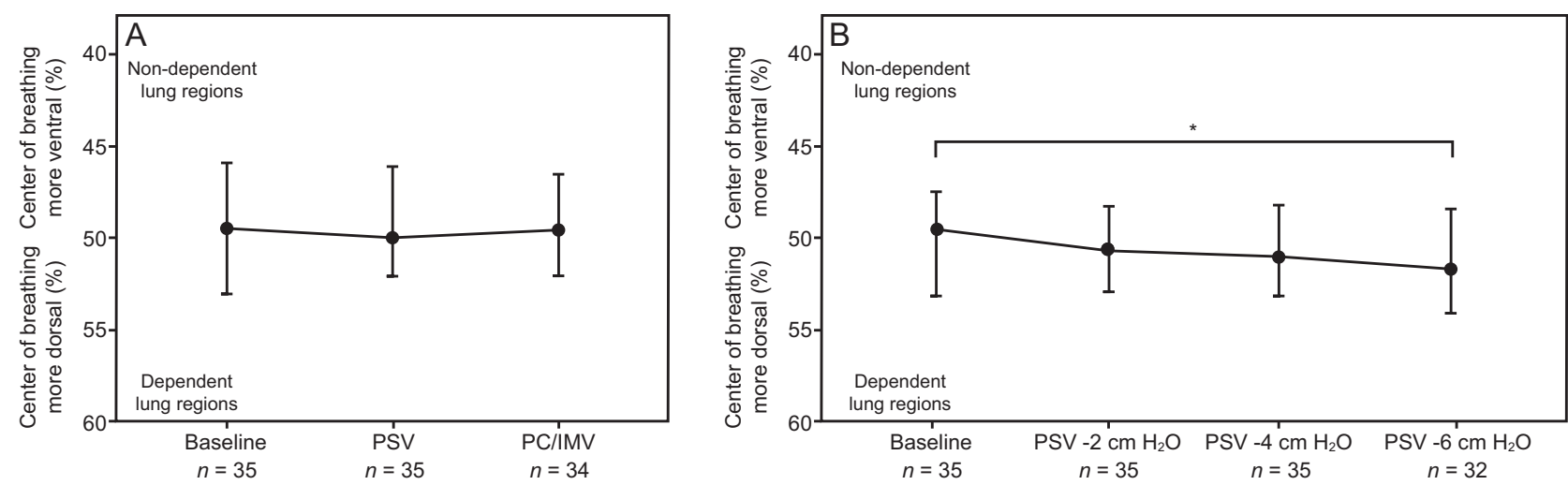

Fig. 2. The effect of the 2 different weaning methods $(A)$ and reduction of pressure support $(B)$ on the center of ventilation. The amount of pressure support during baseline measurement while downgrading the support is in accordance with the level of support used in the spontaneous breathing mode. PSV = pressure support ventilation. PC/SIMV = pressure-controlled (PC)/synchronized intermittent mandatory ventilation (SIMV) with a set mandatory breath rate at $25 \%$ of the rate before enrolment. *Noted as a statistical significance $<.05$.

\section{Discussion}

We showed that in spontaneously breathing intubated children there was no gravity-dependent effect on $\mathrm{V}_{\mathrm{T}}$ distribution and that there was a homogeneous $\mathrm{V}_{\mathrm{T}}$ distribution throughout the lung. Ventilation liberation by means of only CPAP/PSV compared to a mode with mandatory ventilator breaths did not result in clinically relevant changes in $V_{T}$ distribution or EELV. The occurrence of pendelluft could not be demonstrated. Our findings may contribute to a better understanding of ventilator liberation in pediatrics.

Our findings on the distribution of the coefficient of variation are in contrast with observations made in animal studies and mechanically ventilated adults. ${ }^{89}$ The effect of gravity may be less noticeable due to smaller circumference of the pediatric thorax. Also, the pediatric thorax has a more circular shape, at least partially explaining that the coefficient of variation is more in the middle part of the thorax. ${ }^{12}$ The lower elastic recoil in children may further cause a shift to the more anterior parts of the lung. ${ }^{29}$ Recently, Inay and colleagues reported ${ }^{30}$ similar findings on the coefficient of variation in 25 children who had either CSV or no positive-pressure support. However, they also reported that under controlled ventilation the coefficient of variation was more directed toward the nondependent zones. This difference with our findings can most likely be explained by the fact that subjects in our study were much younger, thereby eliminating the effect of gravity and the possible use of sedatives in the study mentioned. This is because especially younger children have a higher chest wall compliance, making those infants having a significantly lower relaxation volume (ie, EELV). Under normal circumstances, children breathe from an EELV that is higher than the relaxation volume; but when sedated, this elevated EELV is changed and in combination with the higher tendency of the airways to collapse causes a breathing pattern that is similar to that of adults with preferential ventilation of the nondependent lung regions. ${ }^{31}$ Another explanation might be that there were differences in how much the subjects breathed spontaneously between our baseline measurements and the measurements under controlled ventilation in their study. Interestingly, studies in preterm infants did show a gravity-dependent effect of $\mathrm{V}_{\mathrm{T}}$ distribution. Frerichs et $\mathrm{al}^{32}$ studied 12 unsedated and healthy neonates (10 were preterm) and found that different body position affects the topographical distribution during spontaneous breathing, a finding subscribed by Riedel et $\mathrm{al},{ }^{33}$ who compared the ventilation inhomogeneity between preterm and term-born infants during quiet natural sleep breathing in supine position. They found that in the preterm infant the tidal breath was preferentially distributed to the anterior parts of the lung. . $^{32,33}$

Traditionally, children are weaned from the ventilator by reducing the level of ventilatory support to a certain minimum. An extubation readiness test can be performed to assess if the patient can be liberated from the ventilator. Most extubation readiness tests make use of some pressure support. This minimum level of support is not only applied because of the perceived added resistance of the endotracheal tube, but clinicians may also fear that patients will become tachypneic and develop shallow breathing when insufficient levels of support are delivered. ${ }^{25}$ Our study results may at least partially prove otherwise. First, we did not find a change in EELV between partial ventilatory support or CSV. Second, although EELV decreased significantly when pressure support was decreased, this difference is in our view clinically irrelevant since we did not observe clinically relevant changes in oxygenation (ie, $\mathrm{S}_{\mathrm{PO}_{2}}$ and $\mathrm{F}_{\mathrm{IO}_{2}}$ ). At the same time, it may be argued that our results were confounded by the relatively high level of pressure support that was set before it was reduced. In perspective, 


\section{Global and Regional V $V_{T}$ In Mechanically Ventilated ChildRen}
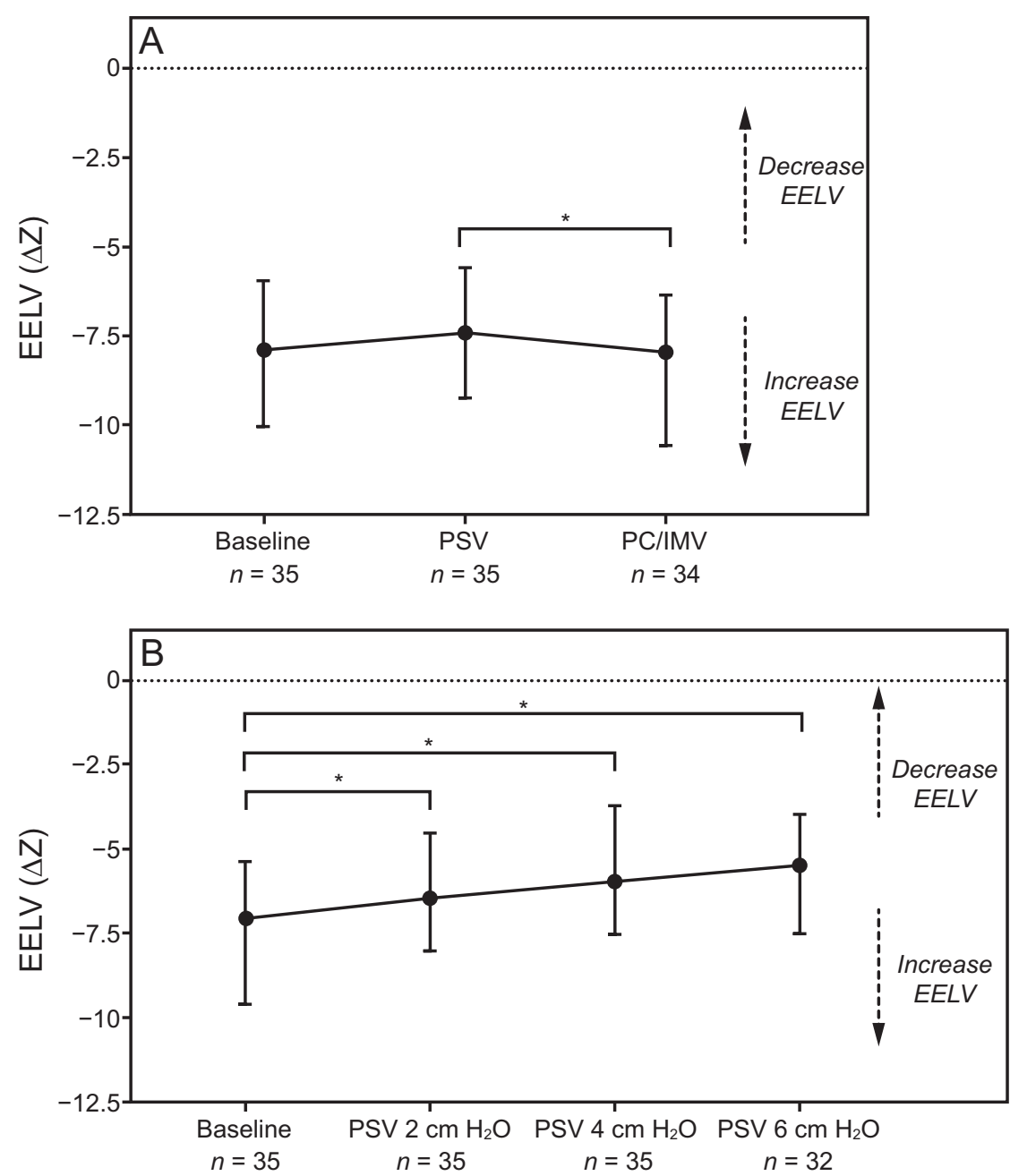

Fig. 3. The effect of the 2 different weaning methods $(A)$ and reduction of pressure support $(A)$ on end-expiratory lung volume (EELV). The amount of pressure support during baseline measurement while downgrading the support is in accordance with the level of support used in the spontaneous breathing mode. PSV = pressure support ventilation. PC/SIMV = pressure-controlled (PC)/synchronized intermittent mandatory ventilation with a set mandatory breath rate at $25 \%$ of the rate before enrollment. *Noted as a statistical significance $<.05$.

most of the extubation readiness tests are executed with too much pressure support and thereby masking the physiological effect of such tests. ${ }^{34}$ Future studies should, therefore, compare changes in $\mathrm{V}_{\mathrm{T}}$ distribution and EELV during CPAP with and without added pressure support, especially since the added resistance by the endotracheal tube is negligible..$^{35,26}$

We did not observe the intrabreath movement of gas from the nondependent to the dependent lung regions without a change in $\mathrm{V}_{\mathrm{T}}$, a phenomenon that is known as pendelluft. ${ }^{37}$ This might be explained by the absence of interalveolar pores and/or bronchoalveolar channels in the pediatric, immature lung. ${ }^{38}$ On the other hand, it is vigorous breathing in the presence of severe lung injury that might give rise to pendelluft, but the subjects in our study had no or mostly resolved lung injury. ${ }^{3,39,40}$ Future studies, therefore, are needed to examine the effects of vigorous, potentially injurious spontaneous breathing in the pediatric context.

To our best of knowledge, this is the first prospective pediatric study examining global and regional lung volume changes using EIT during ventilation liberation. However, several limitations of our study are to be mentioned. Our clinical study was a designed single-center study that may limit the generalizability of our findings, although our unit is comparable to most large units globally. Subjects were enrolled into our study when the attending physician deemed the patient eligible for weaning. However, it is known that the time point when weaning starts is ill defined in ventilated children. ${ }^{25}$ This may have caused a selection bias with less stable respiratory patients not included. Also, we made EIT 


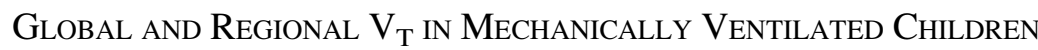
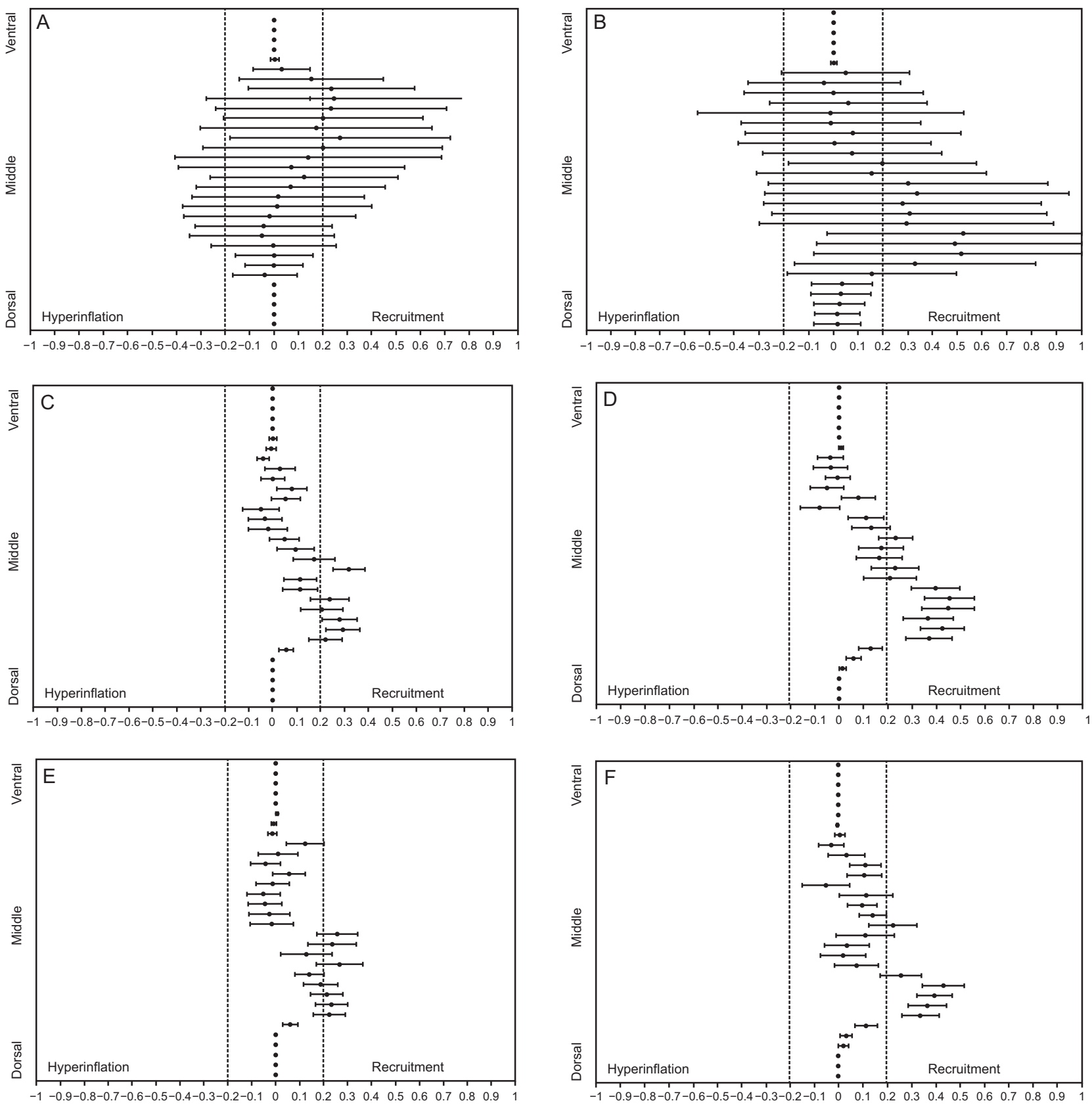

Fig. 4. Polynomial coefficients of regional versus global filling characteristics. Left lung (A, C, and $E)$ and right lung (B, D, and $F)$. $A$ and $\mathrm{B}$ : baseline, $\mathrm{C}$ and $\mathrm{D}$ : pressure support ventilation, $\mathrm{E}$ and $\mathrm{F}$ : pressure control/synchronized intermittent mandatory ventilation with a set mandatory frequency at $25 \%$ of the frequency before enrollment. Data are expressed as median interquartile range (IQR). Polynomial coefficients of regional versus global filling during different approaches of weaning in the dorsal to ventral direction by making use of electrical impedance tomography measurements.

recordings for $1 \mathrm{~min}$, but this might have resulted in a variable number of patient breaths during this period, potentially causing bias. Nonetheless, we think this can be neglected since most subjects in our study were young and had a comparable breathing frequency.

An important limitation of EIT is the fact that the images do not necessarily detect ventilation differences in the whole cephalocaudal direction. They show changes in electrical impedance derived from a 3-dimensional chest slice because regions out of the electrode plane also affect the measured electrical potential differences and influence the generated images. ${ }^{41}$ However, this does not preclude the underestimation of possible ventilation heterogeneity by EIT in remote chest regions. Furthermore, positioning of the EIT electrodes 


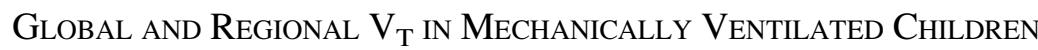
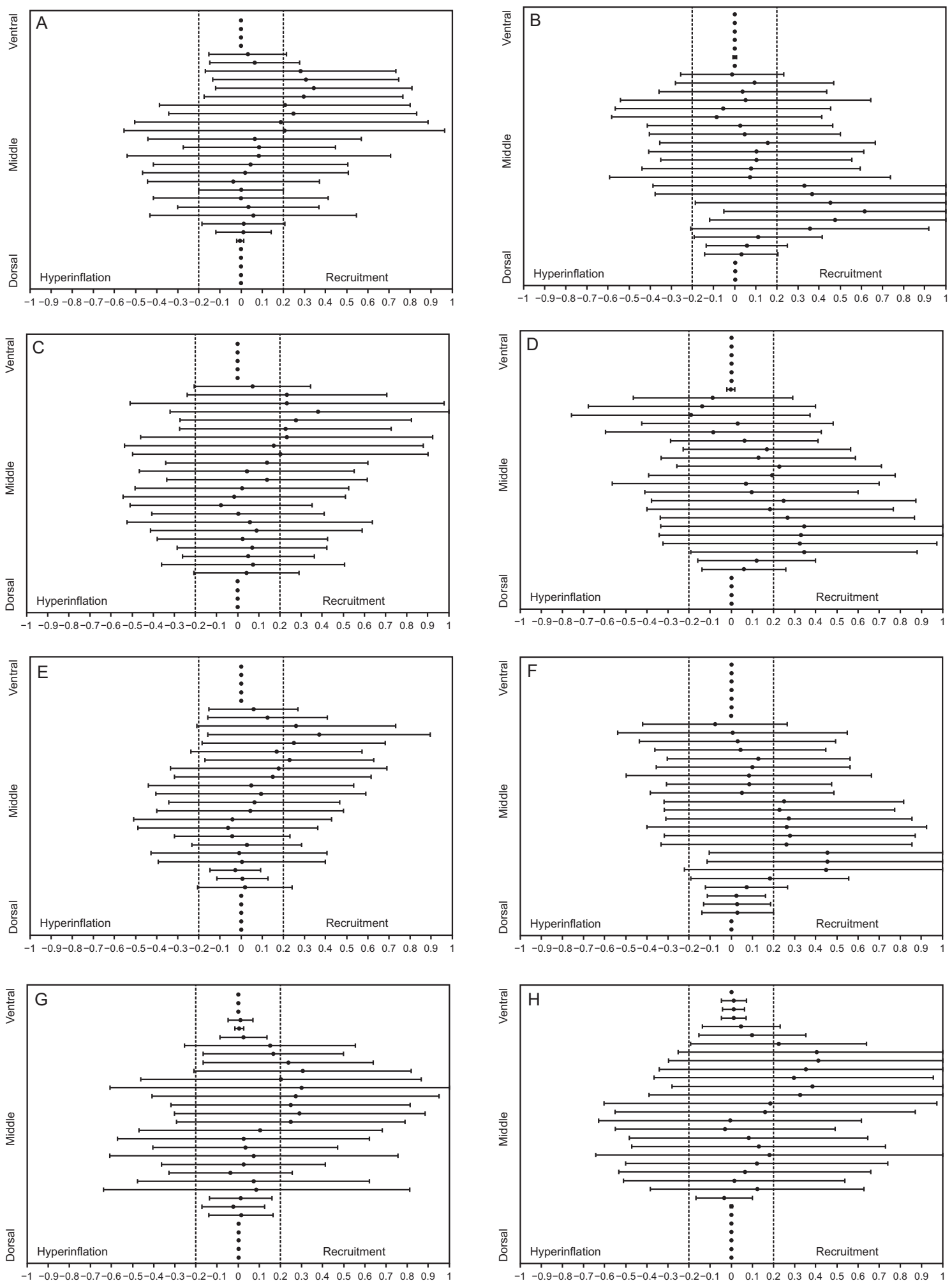

Fig. 5. Polynomial coefficients of regional versus global filling characteristics. Left lung (A, $C, E$, and $G)$ and right lung $(B, D, F$, and $H)$. A and $B$ : baseline, $\mathrm{C}$ and D: pressure support ventilation (PSV) $-2 \mathrm{~cm} \mathrm{H} 2 \mathrm{O}$, E and F: PSV $-4 \mathrm{~cm} \mathrm{H} 2 \mathrm{O}$, and G and $\mathrm{H}$ : PSV $-6 \mathrm{~cm} \mathrm{H}_{2} \mathrm{O}$. Data are expressed as median interquartile range (IQR). Polynomial coefficients of regional versus global filling during gradual reduction of PSV in the dorsal to ventral direction by making use of electrical impedance tomography measurements.

Copyright (C) 2021 Daedalus Enterprises ePub ahead of print papers have been peer-reviewed, accepted for publication, copy edited and proofread. However, this version may differ from the final published version in the online and print editions of RESPIRATORY CARE 


\section{Global and Regional $V_{T}$ In Mechanically Ventilated ChildRen}

is important when assessing EELV; this should be kept in mind when comparing studies that used other techniques to study EELV such as multibreath washout.

\section{Conclusions}

Global and regional $\mathrm{V}_{\mathrm{T}}$ distribution were not gravity dependent and homogeneously distributed in mechanically ventilated children during the ventilator liberation phase, irrespective of ventilator mode or level of pressure support. These findings may help in a better understanding of the pediatric ventilator liberation process.

\section{REFERENCES}

1. Brochard L, Slutsky A, Pesenti A. Mechanical ventilation to minimize progression of lung injury in acute respiratory failure. Am J Respir Crit Care Med 2017;195(4):438-442.

2. Yoshida T, Amato MBP, Kavanagh BP, Fujino Y. Impact of spontaneous breathing during mechanical ventilation in acute respiratory distress syndrome. Curr Opin Crit Care 2019;25(2):192-198.

3. Yoshida T, Uchiyama A, Matsuura N, Mashimo T, Fujino Y. The comparison of spontaneous breathing and muscle paralysis in two different severities of experimental lung injury. Crit Care Med 2013;41 (2):536-545.

4. Froese AB, Bryan AC. Effects of anesthesia and paralysis on diaphragmatic mechanics in man. Anesthesiology 1974;41(3):242-255.

5. Putensen C, Muders T, Varelmann D, Wrigge H. The impact of spontaneous breathing during mechanical ventilation. Curr Opin Crit Care 2006;12(1):13-18.

6. Hedenstierna G, Tokics L, Lundquist H, Andersson T, Strandberg A, Brismar B. Phrenic nerve stimulation during halothane anesthesia. Effects of atelectasis. Anesthesiology 1994;80(4):751-760.

7. Putensen C, Hering R, Muders T, Wrigge $H$. Assisted breathing is better in acute respiratory failure. Curr Opin Crit Care 2005;11(1):63-68.

8. Putensen C, Mutz NJ, Putensen-Himmer G, Zinserling J. Spontaneous breathing during ventilatory support improves ventilation-perfusion distributions in patients with acute respiratory distress syndrome. Am J Respir Crit Care Med 1999;159(4):1241-1248.

9. Wrigge H, Zinserling J, Neumann P, Defosse J, Magnusson A, Putensen C, et al. Spontaneous breathing improves lung aeration in oleic acid-induced lung injury. Anesthesiology 2003;99(2):376-384.

10. Xia J, Sun B, He H, Zhang H, Wang C, Zhan Q. Effect of spontaneous breathing on ventilator-induced lung injury in mechanically ventilated healthy rabbits: a randomized, controlled, experimental study. Crit Care 2011;15(5):R244.

11. Humphreys S, Pham TM, Stocker C, Schibler A. The effect of induction of anesthesia and intubation on end-expiratory lung level and regional ventilation distribution in cardiac children. Paediatr Anaesth 2011;21(8):887-893.

12. Wilsterman MEF, de Jager P, Blokpoel R, Frerichs I, Dijkstra SK, Albers M, et al. Short-term effects of neuromuscular blockade on global and regional lung mechanics, oxygenation, and ventilation in pediatric acute hypoxemic respiratory failure. Ann Intensive Care 2016;6(1):103.

13. Richard JC, Pouzot C, Gros A, Tourevieille C, Lebars D, Lavenne F, et al. Electrical impedance tomography compared to positron emission tomography for the measurement of regional lung ventilation: an experimental study. Crit Care 2009;13(3):R82.

14. Schibler A, Calzia E. Electrical impedance tomography: a future item on the "Christmas Wish List" of the intensivist? Intensive Care Med 2008;34(3):400-401; author reply 583.
15. van Genderingen HR, van Vught AJ, Jansen JR. Estimation of regional lung volume changes by electrical impedance pressures tomography during a pressure-volume maneuver. Intensive Care Med 2003;29 (2):233-240.

16. Wolf GK, Arnold JH. Noninvasive assessment of lung volume: respiratory inductance plethysmography and electrical impedance tomography. Crit Care Med 2005;33(3 Suppl):S163-9.

17. Bodenstein M, David M, Markstaller K. Principles of electrical impedance tomography and its clinical application. Crit Care Med 2009;37 (2):713-724.

18. Hinz J, Gehoff A, Moerer O, Frerichs I, Hahn G, Hellige G, et al. Regional filling characteristics of the lungs in mechanically ventilated patients with acute lung injury. Eur J Anaesthesiol 2007;24(5):414-424.

19. Muders T, Luepschen H, Putensen C. Impedance tomography as a new monitoring technique. Curr Opin Crit Care 2010;16(3):269-275.

20. Brown BH. Electrical impedance tomography (EIT): a review. J Med Eng Technol 2003;27(3):97-108.

21. Kneyber MC, van Heerde M, Twisk JW, Plotz FB, Markhors DG. Heliox reduces respiratory system resistance in respiratory syncytial virus induced respiratory failure. Crit Care 2009;13(3):R71.

22. Milic-Emili J, Henderson JA, Dolovich MB, Trop D, Kaneko K. Regional distribution of inspired gas in the lung. J Appl Physiol 1966;21(3):749-759.

23. Pollack MM, Patel KM, Ruttimann UE. PRISM III: an updated pediatric risk of mortality score. Crit Care Med 1996;24(5):743-752.

24. Khemani RG, Smith LS, Zimmerman JJ, Erickson S, Pediatric Acute Lung Injury Consensus Conference G. Pediatric acute respiratory distress syndrome: definition, incidence, and epidemiology: proceedings from the pediatric acute lung injury consensus conference. Pediatr Crit Care Med 2015;16(5 Suppl 1):S23-40.

25. Kneyber MCJ, de Luca D, Calderini E, Jarreau PH, Javouhey E, Lopez-Herce J, et al; section Respiratory Failure of the European Society for Paediatric and Neonatal Intensive Care. Recommendations for mechanical ventilation of critically ill children from the Pediatric Mechanical Ventilation Consensus Conference (PEMVECC). Intensive Care Med 2017;43(12):1764-1780.

26. Wolf GK, Grychtol B, Frerichs I, van Genderingen HR, Zurakowski $\mathrm{D}$, Thompson JE, et al. Regional lung volume changes in children with acute respiratory distress syndrome during a derecruitment maneuver. Crit Care Med 2007;35(8):1972-1978.

27. Frerichs I, Hahn G, Hellige G. Gravity-dependent phenomena in lung ventilation determined by functional EIT. Physiol Meas 1996;17 Suppl 4A:A149-57.

28. Frerichs I, Hahn G, Hellige G. Thoracic electrical impedance tomographic measurements during volume-controlled ventilation effects of tidal volume and positive end-expiratory pressure. IEEE Trans Med Imaging 1999;18(9):764-773.

29. Davies H, Kitchman R, Gordon I, Helms P. Regional ventilation in infancy. Reversal of adult pattern. N Engl J Med 1985;313(26):16261628.

30. Inany HS, Rettig JS, Smallwood CD, Arnold JH, Walsh BK. Distribution of ventilation measured by electrical impedance tomography in critically ill children. Respir Care 2020;65(5):590-595.

31. Mansell A, Bryan C, Levison H. Airway closure in children. J Appl Physiol 1972;33(6):711-714.

32. Frerichs I, Schiffmann H, Oehler R, Dudykevych T, Hahn G, Hinz J, et al. Distribution of lung ventilation in spontaneously breathing neonates lying in different body positions. Intensive Care Med 2003;29 (5):787-794.

33. Riedel T, Kyburz M, Latzin P, Thamrin C, Frey U. Regional and overall ventilation inhomogeneities in preterm and term-born infants. Intensive Care Med 2009;35(1):144-151.

34. Sklar MC, Burns K, Rittayamai N, Lanys A, Rauseo M, Chen L, et al. Effort to breathe with various spontaneous breathing trial techniques. 


\section{Global and Regional $V_{T}$ In Mechanically Ventilated ChildRen}

A physiologic meta-analysis. Am J Respir Crit Care Med 2017;195 (11): 1477-1485

35. Khemani RG, Hotz J, Morzov R, Flink RC, Kamerkar A, LaFortune $\mathrm{M}$, et al. Pediatric extubation readiness tests should not use pressure support. Intensive Care Med 2016;42(8):1214-1222.

36. van Dijk J, Blokpoel RGT, Koopman AA, Dijkstra S, Burgerhof JGM, Kneyber MCJ. The effect of pressure support on imposed work of breathing during pediatric extubation readiness testing. Ann Intensive Care 2019;9(1):78.

37. Yoshida T, Torsani V, Gomes S, De Santis RR, Beraldo MA, Costa EL, et al. Spontaneous effort causes occult pendelluft during mechanical ventilation. Am J Respir Crit Care Med 2013;188(12):1420-1427.
38. Macklem PT. Airway obstruction and collateral ventilation. Physiol Rev 1971;51(2):368-436.

39. Rossi FS, Costa ELV, Iope DDM, Pacce PHD, Cestaro C, Braz LZ, et al. Pendelluft detection using electrical impedance tomography in an infant. Keep those images in mind. Am J Respir Crit Care Med 2019;200(11):1427-1429.

40. Santini A, Mauri T, Dalla Corte F, Spinelli E, Pesenti A. Effects of inspiratory flow on lung stress, pendelluft, and ventilation heterogeneity in ARDS: a physiological study. Crit Care 2019;23(1):369.

41. Rabbani KS, Kabir AM. Studies on the effect of the third dimension on a two-dimensional electrical impedance tomography system. Clin Phys Physiol Meas 1991;12(4):393-402. 